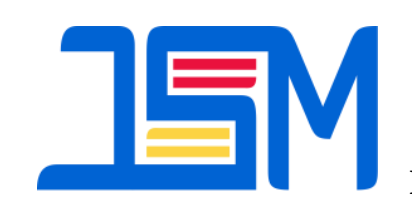

JAMBURA SCIENCE OF MANAGEMENT

Homepage : http://ejurnal.ung.ac.id/index.php/jsm

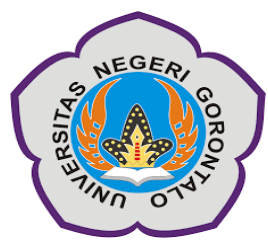

\title{
Workplace Stress: Issues And Management
}

\author{
Ida Miharti \\ Economic Faculty, Universitas Andalas, Padang, West Sumatera, Indonesia \\ Limau Manis, Pauh Sub-District, Padang City, Postal Code 25175 \\ E-mail: idamiharti@yahoo.co.id
}

\section{Abstract:}

This paper tries to show that workplace stress should be managed. Workplace stress can be influences individual life, not only in its family but also in its society. Work and nonwork factor can be interacting each other, that can be made stress become. So, it is important to find how to manage individual stress, especially in workplace stress.

\section{Keywords: Workplace Stress, Management}

One issue that needs to be addressed at this time is to balance between roles in work and roles in the family, especially for women. We can see today that many women have entered the workforce, so they have a dual role, as workers in the office and as housewives at home and must take care of children if they already have children. This double role can certainly cause problems if the woman is unable to manage both roles well. If there is an imbalance, it can cause stress, dissatisfaction with work, both in the office and at home.

Well, what is meant by stress. According to Gibson, Ivancevich, Donnelly and Konopaske (2003) in his book defined that; stress is a feeling of tension, anxiety or anxiety. Or it can also be defined as "the experience of special demands being placed on the individual".
Special demand here is intended as something unusual, a threat physically or psychologically or outside of experience. In other words, stress can be defined as a stimulus (stimulus) or response (response). So we can conclude that stress is a response made by an individual in identifying the condition of the stimulus (action, situation, event) as a stressor (potential threat from outside).

Stress in each individual has different levels. An individual who has exactly the same tasks as another individual will have different levels of stress, depending on the individual's characteristics. Three key factors that can determine whether an experience can cause stress are:

1. The importance of an event (importance) 
Related to how individuals see the significance of an event they experienced. For example, if an individual is suspended from work. If the individual considers the event as something important, then this event can cause stress in the individual.

2. Uncertainty (uncertainty)

Related to the lack of clarity about what will happen. For example, the existence of rumors or issues that will be terminated at some employees will be more stressful than if it was known that certain information would indeed be laid off at some employees.

3. Duration

This is a significant factor, related to the length of time in dealing with an event. For example, if an individual is given a task that he dislikes within two days it will certainly have a lower stress level compared to an individual who is given a task that he dislikes in six months or a long period of time.

Work is a major part of our lives, and work carried out in the office and at home has interdependence. The difference between stress in the office and at home has always been a problem for individuals who have multiple roles. There are three categories of stressors, namely:

1. Individual Stressor

Stress at the individual level is the most studied in various categories. Stress in individuals generally occurs because there is a conflict between the fulfillment of an expectation against the fulfillment of other expectations. In a company, conflicts can occur between the supervisor and his subordinates if the supervisor has subordinates who do not match the work performed, so that it can threaten the achievement of the target results set by the supervisor. In addition, the dual role of an individual (in the office and at home) can also lead to conflicts that lead to stress if not managed properly. Examples of conflicts between work and family for example; pressures that make work late, bring office work home, spend more time working outside for field workers, etc. When a couple in a family both works, then this will be able to add to the conflict when one of their careers has increased and can have a negative influence on their partner's career improvement. Besides conflicts can also arise when a person experiences overload. There are two forms of overload, namely qualitative and quantitative. Qualitative overload occurs when individuals feel they do not have enough ability to be able to complete a task that demands too high performance. While quantitative overload occurs when individuals feel they do not have enough time to be able to do several tasks at the same time. According to research results, quantitative overload can cause changes in the body, such as an increase in cholesterol. So that if an individual is stressed, it will not only have a negative impact on his performance but also on his health.

2. Group and Organizational Stressor 
If seen in groups and organizations, there are some main things that can be a significant stressor. First, participation. Participation is related to the expansion of knowledge, opinions and ideas possessed by an individual who is included in the decision making process. Organizations that do not encourage or allow participation will lead to frustration. Second, relationships within and between groups. Relationships that are problematic in groups can reduce communication and performance which ultimately increases stress. Third, organizational politics. High political behavior in organizations can cause competition in the organization and become a source of stress for employees. Fourth, organizational culture. If the organizational culture built by top executives is not good, it can cause stress for its employees. Fifth, lack of feedback on performance. Organizations that do not provide feedback on the performance of their employees will cause stress on these employees, because he will feel unnoticed and not appreciated. Sixth, career development opportunities are inadequate. If in an organization its employees have very few opportunities to develop their careers. Seventh, downsizing. For example by early retirement. This can cause stress for both individuals and organizations.

3. Nonwork Stressor

Is a stressor caused by factors outside the organization. For example, balancing tasks at work and at home, taking courses while working, increasing number of children, and others. These factors can trigger stress.

Stress experienced by an individual can provide a varied effect, which can affect the work, psychological, cognitive, behavior and health of an individual. Psychological influences that can be caused for example anxiety, frustration, lethargy, lack of confidence, easy emotions / attacks and depression. While cognitive influences that can be caused for example, lack of concentration, inability to make decisions, mental blocks and reduce attention to something. Influence on behavior that can be caused for example, using alcohol and drugs, blowing up anger and behavior that only follows the conscience. And an example of the effect of stress on health is that it can increase stomach acid, increase heart rate and raise blood pressure.

Various conditions, behaviors and characteristics can act as moderators of stress, including variables such as age, gender and endurance. There are three types of stress moderators that can represent this, namely:

1. Personality

An individual's personality can be a moderator for the onset of stress. For example, individuals who have an open and sociable nature will have many friends with a wide network. So if he has a problem, he will have many friends who will help him through this stressful period. Likewise with individuals who have high self- 
efficacy, then he will feel confident that he has the ability to solve a problem and produce the best performance.

2. Type A Behavior

According to the results of research by Meyer Friedman and Ray Rosenman, what is meant by type A behavior is behavior that has the following characteristics: aggressive, ambitious, impatient, does not like to wait, in a hurry in talking, always trying to achieve something in a short time . Individuals with type A behaviors will be prone to stress which can affect their health and can cause insomnia and depression.

3. Social Support

Social support can be interpreted as comfort, assistance or information received by someone through relationships with individuals and groups formally or informally. Social support can be done in the form of emotional support (giving attention, listening), assessment support (giving feedback) or information support (giving advice, giving advice, giving directions). Social support is the most effective stress moderator because it can withstand the negative effects of stressors by providing predictions, goals and expectations in situations that are threatening and confusing.

\section{PREVIOUS RESEARCH}

There have been many studies that have examined the workplace stress.
Schieman, McBrier and Gundy (2003) have conducted research on Home-toWork Conflict, Work Qualities and Emotional Distress. In this study they examined both male and female workers in the Toronto, Canada area. Based on this research it was found that home-to-work conflict was positively related to anxiety and depression. This is because men and women who are married have two dual roles that they must be able to carry out at once. Especially for women who have young children and both partners work in an office. In this case, women are the ones who experience the most conflicts between their roles at home and in the office, because even in the office women have the same demands as men in doing their work in the office full time. At this time, things like this are indeed a challenge that must be done well in accordance with the demands of the times, where a married male / female worker must be able to balance his attention in carrying out the role of parent and role as worker. As more and more women work full time, roles at home and in the office often compete with one another, which can ultimately increase the potential for stress-related spillovers. Tension in the home can create conflict that can affect work in the office, so stress brought from home can also cause stress on office work. From the research results of Schieman, et.al (2003) found that hometo-work conflict and distress have a strong relationship with people who have a lot of autonomy in their work, in women who do routine tasks and in men who work in dangerous environment. 
Then Grzywacz, Almeida, McDonald (2002) conducted research on the Work-Family Spillover and Daily Reports of Work and Family Stress in the Adult Labor Force. If Schieman, et.al (2003) sees Home-to-Work Conflict, then Grzywacz, et.al (2002) sees the opposite, namely Work-to-Family Conflict. The quality of compatibility between work and family is a major issue in family life today. Little is known about the work-family experience of workers which can become something more prominent in the workforce. Family life theory is an important central focus in the context of social structure that requires a valuable framework for examining work-family spillovers among mature workers. The accumulation of personal experience, skills and expertise will be able to encourage even greater integration in work and family. The theory of family life also emphasizes the importance of individual location in the status hierarchy of social structures and social relations. For example, women often find imbalance in responsibilities in the family and household when compared to men, and they are employed in "bad" jobs. In this case it is also seen that stress at work can affect one's mood when at home. One of them can interfere with activities at home if work in the office is taken home and done at home. An individual who cannot control himself well if he gets into trouble at work or gets a reprimand from a boss will bring these emotions home.

Furthermore, research on workplace stress was also carried out by
Frone, Barnes and Farrel (1994). They examined the Relationship of WorkFamily Conflict to Substance Use Among Employed Mother: The Role of Negative Affect. This research was carried out due to an increase in the number of women entering the workforce, especially those who were married and became parents. Work-family conflict occurs when efforts to fulfill the role of worker are interfered with the person's ability to meet family needs and vice versa. Because work-family conflict reflects the overall compatibility between work and family life. This has been conceptualized as an important source of stress that can affect individual health. For example, identity theory proposes that work-family conflicts can be potential stressors because they represent threats and difficulties to identify themselves. Individuals who often have experience of conflicts between work and roles in the family will have more difficult experiences to build and maintain the desire to work and relate to the image of the family and all this will cause health problems. There are still few studies examining the relationship between workfamily conflict on health in women. In the study of Frone, et.al (1994), the main objective is to conduct a more detailed study of the relationship between workfamily conflict with the use of alcohol and cigarettes, especially in women. As we have seen, the role in the office can interfere with the role in the family (workfamily conflict) and vice versa, the role in the family can also interfere with the role in the office (family-work conflict). 
Family-work conflict can lead to dissatisfaction at work (job dissatisfaction) and work-family conflict can lead to family dissatisfaction. The existence of this dissatisfaction can cause psychological distress that can affect health and behavior, one of which is the increased use of alcohol and cigarettes. They use alcohol and cigarettes as an escape from the stress they face.

\section{WRITING PURPOSE}

Workplace stress is a very important topic to be developed and researched, because all of this will be related to individual and organizational performance. Workplace stress experienced by an individual will affect the individual's personal, family and social life, so things need to be managed properly. As we know, stress can arise due to various things such as too much work, being scolded by superiors, computer problems, being chased by deadlines, reducing the number of workers, out of harmony, financial problems, and so on. The factors that cause this stress, both work and nonwork factors interact with each other which causes stress on an individual and his work. So here it is necessary to consider how to manage stress well, so it does not cause negative impacts on individuals, families and organizations. The balance of roles in the office and roles in the family is expected to be achieved well through good management by organizations and individuals individually.

\section{DISCUSSION}

In managing workplace stress, organizations should play a large role and give great attention to their workers. One of them is by creating a friendly work program that balances the role of a worker in the office and in the family. For example, providing a day care center, so that a mother can work quietly in the office without feeling anxious. Another example is creating a flexible work schedule, so that parents still have time to pick up their children from school, can do work at home through telecommuting, completed the facilities in the office, such as providing laundry and cleaning services. It is hoped that a program like this can reduce workers' stress levels.

A sharp and sensitive manager will never ignore the problem of absenteeism and employee turnover, use of drugs in the workplace, decreased performance, decreased quality of production or various other signs that an organization's performance in achieving its goals is not going well. Effective managers will see this incident as a symptom that must be identified and corrected immediately.

Many approaches and programs to prevent and manage stress in organizations. The program is targeted at identifying and modifying work stressors, involving workers in order to understand and modify stresses and their impacts, providing support to workers to overcome the negative effects of stress. In a work environment that is undergoing rapid change, this type of target will be difficult 
to achieve. However, training, education and knowing many things about workforce will be able to help management determine how a job should be done. Several improvement programs are carried out to achieve this target, including training programs to manage and deal with stress, redesign work to minimize stressors, change management styles from one to be a lot of support and train to help workers achieve their goals, create more flexible working hours and pay more attention to the balance between work and family by paying attention to child and elder care, better communication and building teamwork, providing better feedback on employee performance and management expectations. All of this is some effort to prevent and manage stress. The difference between preventing stress and managing stress is important. Stress prevention is focused on monitoring and eliminating stressors that can cause stress. While managing stress is a procedure to help individuals cope with and reduce stress experienced effectively.

Stress is a consequence of the relationship between the individual and his work environment. Therefore it is necessary to create a person-environment fit (P-E fit). This approach focuses on two dimensions, the first is an expansion of work that provides formal and informal rewards that are matched to individual needs. If there is a mismatch, then this can cause stress. The second type is to match the skills, abilities and experience of workers with the needs and requirements proposed by the company leadership.
Ideally, these two dimensions begin before an individual joins the organization where he will work. If a match has been found, the organization's socialization of the new employee needs to be carried out. Socialization is the process by which individuals learn and internalize the values, expected behaviors and social knowledge that are essential for becoming effective members of an organization.

There have been many activities undertaken to improve P-E fit, an increasing number of organizations that have developed stress prevention and management programs specifically. Some of these programs focus on specific problems such as alcohol or drug use, career counceling, job relocation or burnout. There are two specific types of organizational programs that have become popular in the last two decades, namely:

1. Employee Assistance Programs (EAPs)

It is a program designed to deal with stress related to work and non-work problems, including difficulties in behavior and emotions, marital problems and other personal problems. In general, the program undertaken is to diagnose problems faced by employees, conduct counseling or therapy if needed, periodically examine employees, provide education and advice in dealing with stress. Workers believe that good health owned by employees will give something good for the organization. To succeed in undergoing the EAPs program is trust, where workers must 
believe that this program can really help them in real terms, confidentiality is maintained and this program has no negative implications for future work.

2. Wellness Programs

The program is also referred to as a health improvement program, focusing on the physical and mental health of employees. In this case not only identifying diseases but also lifestyles that can affect health. One example of this program is identifying and controlling hypertension, stopping smoking, physical exercise, controlling nutrition and diet and managing work and personal stress.

These two programs do not guarantee positive results for workers or organizations. There are many other factors that can determine the success of this program, some of which are important including support from top management, union support and participation, ongoing efforts, actually implementing and maintaining what has been programmed, stating clear goals, employees can participate freedom without pressure and participation of these employees does not affect their presence in the organization.

If the organizational approach to preventing and managing stress has been explained earlier, then after this we look at the individual approach to preventing and managing stress. This needs to be done because the individual does not have to be too dependent on his organization, but also must actively try to cope with the stress he faces. There are several techniques that individuals can do in preventing and managing stress, namely:

1. Cognitive Techniques

Individual responses to stressors are mediated by cognitive or thinking processes, such as expectations, beliefs and assumptions. This technique teaches individuals to think positively of the problem at hand. For example, by teaching how to change the way of thinking; that if you do not get a promotion at work, it does not mean that your career will end soon. So this technique seeks to help individuals be more in control of their relationship to the stressor they face so that it does not cause stress.

2. Relaxation training

The purpose of this approach is to make individuals more calm both psychologically and physiologically. Psychologically successful relaxation will result in an increased sense of health, calmness, reduced tension and anxiety and physiologically lowers blood pressure, breathing and regular heart rate. Relaxation techniques are focused on breathing exercises, muscle relaxation, combining relaxation and muscle meditation.

3. Meditation

The most common meditation is transcendental meditation (TM). The basic procedure in doing TM is very easy but the benefits provided are very broad. Based on studies conducted found that TM is associated with a reduction in heart rate, low oxygen 
consumption and reduce blood pressure.

4. Biofeedback

Is a technique where the individual can control the processes of the inner body. Its role can be seen from the functioning of the body properly. Biofeedback training is useful for reducing anxiety, lowering stomach acid, controlling blood pressure, migraine and headaches and generally reducing the negative effects of physiological stress.

\section{CONCLUSION}

Based on the writing above, we can conclude that there is indeed a relationship between home to work conflict and psychological function (Schieman, McBrier, Gundy, 2003). Besides the quality of work can also affect one's personal emotions. Job autonomy, routine activities and noxiousness moderate the relationship between home to work spillover and symptoms of depression and anxiety. The positive relationship between home to work conflict with anxiety and depression is strong when job autonomy is high, although the effect is strong among male workers. In addition, the relationship between home to work conflict with anxiety and depression is strong in women who have routine tasks and in men with a dangerous work environment. So that home to work conflict does cause distress, but the form of influence is different in terms of gender and quality of work. Distress can increase absences and dissatisfaction at work and reduce work productivity.

Besides that, we can also see that the results of the research clearly show the relationship between psychological distress and the use of alcohol and cigarettes. Moreover, research finds that dissatisfaction in the family is positively and directly related to the frequency of alcohol use and can also increase anger or emotions.

Stress if managed properly will have a positive impact on an individual, because he will feel challenged by the difficulties he faces. If he can manage this well, then it can lead to a positive motivation in an individual. But on the other hand, stress can of course also have a negative impact if you are unable to manage the stress properly. As we have seen in the explanation above, stress can have negative consequences in an individual, such as the tendency of accidents, poor concentration, use of drugs, alcohol and cigarettes, and burnout. While the negative consequences for the organization are such as an increase in the number of absences, turnover, an increase in the number of health costs and treatment of employees, a decrease in employee productivity both quantitatively and qualitatively.

Because of the various negative impacts that can be caused this makes the importance of managing stress well, because it can affect the work and tasks at home, especially for workers who have multiple roles. All of this is very useful for the organization, because it can guarantee 
the continuity of the company's operations well. If workers can avoid and deal with stress well, then they can work well, try to provide the best performance, feel satisfaction at work and can help the realization of company goals that have been set. So in this case managers need to pay attention to this, provide facilities for their workers and try to reduce the level of stress experienced by their workers. On the other hand, individual workers should also actively try to be able to prevent and overcome the stress they face without being too dependent on the organization.

\section{REFERENCES}

Frone, R. M., Barnes, M. G. and M. P. Farrel (1994), "Relationship of Work-Family Conflict to Substance Use Among Employed Mothers: The Role of Negative Affect", Journal of Marriage and the Family, Vol. 56, pp. 10191030.
Gibson, J. L., Ivancevich, J. M., Donnelly, J. H.and R. Konopaske, (2003), Organizations: Behavior, Structure, Process, $11^{\text {th }}$ ed. New York: McGraw-Hill.

Grzywacz, G. J., Almeida, M. D. and D. A. McDonald (2002), "WorkFamily Spillover and Daily Reports of Work and Family Stress in the Adult Labor Force", Journal of Family Relations, Vol. 51, pp. 28-36.

Imig, R. D. and G. L. Imig (1995), "Influences of Family Management and Spousal Perceptions on Stressor Pile-up", Journal of Family Relations, Vol. 34, pp. 227-232.

Schieman, S., McBrier, B. D. and K. V. Gundy (2003), "Home-to-Work Conflict, Work Qualities, and Emotional Distress", Sociological Forum, Vol. 18, No. 1, pp. 137161. 